\section{Duodenal and rectal varices as a source of severe upper and lower gastrointestinal bleeding}

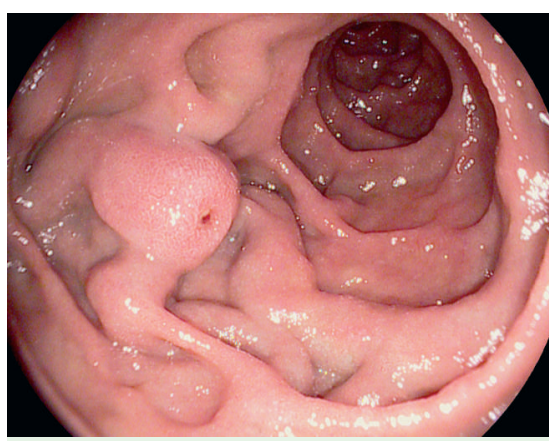

Fig. 1 At the distal border of an extensive variceal convolute in the descending duodenum, a small ulcer was found on the tip of a large varix.

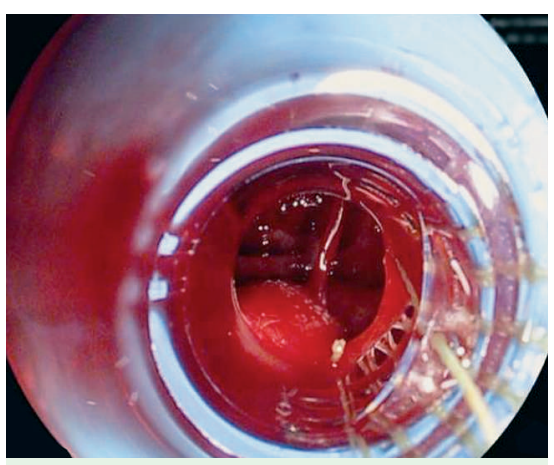

Fig. 2 During band ligation, spurting bleeding was observed.

A 57-year old patient was admitted with hematochezia and hematemesis. The patient's history included portal vein cavernous transformation after posttraumatic splenectomy 34 years ago.

A nonbleeding elevated lesion with a small ulcer was detected in the descending duodenum, within a large convolute of varices ( Fig. 1). Sigmoidoscopy showed considerable amount of fresh blood without a defined bleeding source. Colonoscopy on the following day revealed nonbleeding rectal varices. Duplex ultrasonography confirmed portal vein cavernous transformation. Given both upper and lower gastrointestinal collaterals and bleeding, portosystemic decompression was considered. However, magnetic resonance imaging (MRI) angiography could not identify a patent vein adequate for a transjugular intrahepatic portosystemic stent shunt (TIPSS) or surgical shunting. Therefore, the patient was scheduled for endoscopic therapy.

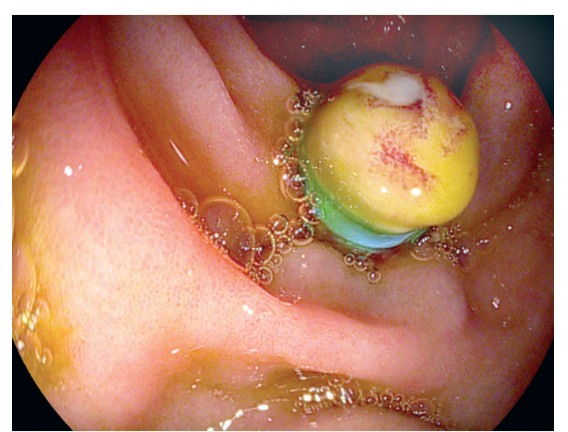

Fig. 3 The bleeding was successfully treated by band ligation (follow-up esophagogastroduodenoscopy 4 hours later). The initial bleeding site is clearly visible on the tip of the pseudopolyp.

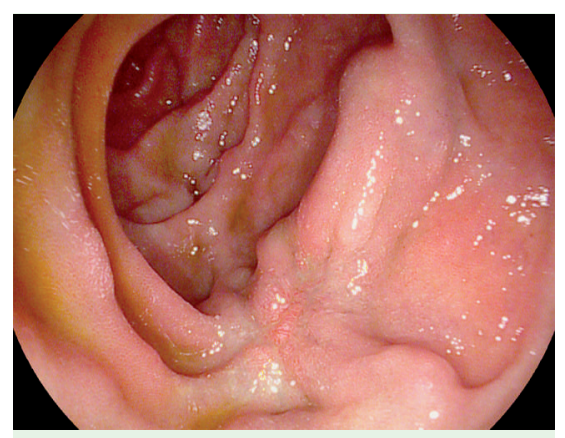

Fig. 4 Four months after band ligation, scarring is seen at the site of the previous ligation in the center of the star-shaped variceal convolute. Residual varices were again band ligated.

During upper endoscopy, a massive amount of blood began to spurt from the previously identified ulcerated area on the varix ( $\bullet$ Fig. 2, $\bullet$ Video 1 ). The bleeding was stopped by band ligation ( Fig. 3). Band ligation of the rectal varices was carried out using a gastroscope in retroflexion. The patient was stable after successful ligation, and propranolol and a proton pump inhibitor were started. Follow-up endoscopy showed scarring after band ligation without stigmata of re-bleeding ( $\bullet$ Fig. 4 ).

Ectopic varices are rare source of gastrointestinal bleeding, and account for 1 $5 \%$ of all variceal bleeding [1]. In a $10-$ year follow-up study, the incidence of duodenal varices in portal hypertension was only $0.4 \%$ [2]. In 750 patients with significantly elevated portal pressure gradient receiving a TIPSS, in 14 years only four were carried out for duodenal and 12 for rectal varices [3]. Duodenal bleed- ing often occurs from erosions on the varix, as in our patient, and has unanimously been reported as severe. The red colour sign seen in oesophageal varices is usually absent [4]. Because of the infrequency of ectopic variceal bleeding, treatment modalities have not been validated prospectively. This case report shows that bleeding from ectopic varices of the upper and lower gastrointestinal tract can be successfully treated by endoscopic band ligation.

Endoscopy_UCTN_Code_CCL_1AB_2AZ_3AD Endoscopy_UCTN_Code_CCL_1AD_2AF

\section{Video 1}

Spurting bleeding from a large varix, which was successfully stopped with band ligation.

M. Goetz, F. K. Rahman, P. R. Galle, R. Kiesslich

Medizinische Klinik und Poliklinik der Johannes Gutenberg-Universität Mainz, Mainz, Germany

\section{References}

1 Norton ID, Andrews JC, Kamath PS. Management of ectopic varices. Hepatology 1998; 28: $1154-1158$

2 Hashizume M, Tanoue K, Ohta M et al. Vascular anatomy of duodenal varices: angiographic and histopathological assessments. Am J Gastroenterol 1993; 88: 1942 - 1945

3 Kochar N, Tripathi D, McAvoy NC et al. Bleeding ectopic varices in cirrhosis: the role of transjugular intrahepatic portosystemic stent shunts. Aliment Pharmacol Ther 2008; 28: 294-303

4 Matsui S, Kudo M, Ichikawa T et al. The clinical characteristics, endoscopic treatment, and prognosis for patients presenting with duodenal varices. Hepatogastroenterology 2008; 55: 959-962

Bibliography

DOI $10.1055 / \mathrm{s}-0029-1214767$

Endoscopy 2009; 41: E169

(c) Georg Thieme Verlag KG Stuttgart · New York . ISSN 0013-726X

\section{Corresponding author}

\section{Goetz, PD Dr. med.}

Medizinische Klinik und Poliklinik der Johannes Gutenberg-Universität Mainz

Langenbeckstr. 1

55131 Mainz

Germany

Fax: +49-6131-175552

mgoetz@mail.uni-mainz.de 